\title{
Concise Syntheses of Violaceoids A and C
}

\author{
Koichi Narita, ${ }^{*, a}$ Ryuhei Kimura, ${ }^{a}$ Hiroka Satoh, ${ }^{a}$ Kazuhiro Watanabe, ${ }^{*, a}$ and Yuichi Yoshimura ${ }^{a, b}$ \\ ${ }^{a}$ Laboratory of Synthetic and Medicinal Chemistry, Faculty of Pharmaceutical Sciences, Tohoku Medical and \\ Pharmaceutical University; 4-4-1 Komatsushima, Aoba-ku, Sendai 981-8558, Japan: and ${ }^{b}$ Laboratory of \\ Organic and Pharmaceutical Chemistry, Faculty of Pharmaceutical Sciences, Tohoku Medical and Pharmaceutical \\ University; 4-4-1 Komatsushima, Aoba-ku, Sendai 981-8558, Japan. \\ Received October 8, 2020; accepted November 6, 2020; advance publication released online November 26, 2020
}

The concise syntheses of two alkylated hydroquinone natural products, violaceoids A and C, were accomplished by a protecting-group-free method employing the commercially available 2,5-dihydroxybenzaldehyde as the starting material. The key strategy of the syntheses is the utilization of alkenylboronic acid as both the coupling and temporary protective reagents to efficiently introduce the requisite alkenyl side chain of violaceoid A. Moreover, the synthesis of violaceoid $\mathrm{C}$ is reported here for the first time.

Key words violaceoid; alkylated hydroquinone; protecting-group-free synthesis; total synthesis

\section{Introduction}

In 2014, Sugawara and colleagues reported the isolation and structural elucidation of a new class of cytotoxic hydroquinones, violaceoids A-F (1-6, Fig. 1), from the culture broth of Aspergillus violaceofuscus Gasperini that was isolated from moss. ${ }^{1)}$ Structurally, violaceoids possess a hydroxymethyl group and a linear alkyl side chain on the same side of the hydroquinone moiety. Although a similar structural feature was observed in the structures of frustulosinol ${ }^{2,3)}$ and aspergentisyls $\mathrm{A},{ }^{4)}$ this substitution pattern is rare among disubstituted hydroquinones isolated from natural sources. ${ }^{5,6)}$ Sugawara and colleagues also reported the cytotoxic activities of violaceoids against five human cancer cell lines (HeLa, MCF-7, Jurkat, MOLT-4, and HCT116) and a mouse macrophage cell line (RAW264.7). Among the violaceoids, violaceoid A (1), which possesses an unsaturated side chain, exhibited the most potent cytotoxic activity against all the six cell lines. Conversely, violaceoids B-D (2-4), which do not possess the olefin moiety on their side chains, exhibited weaker cytotoxic activities than those of $\mathbf{1}$. Therefore, it was suspected that the presence of a conjugated double bond in hydroquinone was essential<smiles>CCCCC/C=C/c1c(O)ccc(O)c1CO</smiles>

violaceoid $A(1)$<smiles>CCCCCCCc1c(O)ccc(O)c1CO</smiles>

violaceoid C (3)<smiles>CCCCC/C=C/C1=C(CO)C(=O)C[C@H](O)[C@H]1O</smiles>

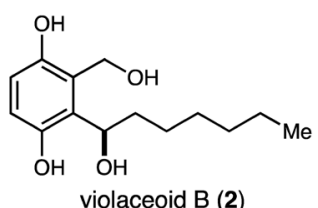

violaceoid B (2)
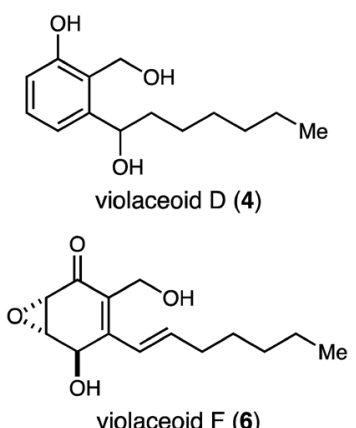

Fig. 1. Structures of Violaceoids A-F (1-6) for cytotoxicity. The first total syntheses of $\mathbf{1}$ and $\mathbf{2}$ were performed by Shiina and colleagues in 2018, and the absolute configuration of $\mathbf{2}$ was established by its synthesis.? ${ }^{7)}$ They utilized 3,6-dihydroxyphthalonitrile as a starting material, and the synthetic route required a relative multistep sequence involving protection-deprotection and oxidation-reduction steps (1: 10 steps, 11\% overall yield; 2: 21 steps, including several repetitive kinetic resolutions and acetonide deprotection steps and $1.3 \%$ overall yield). In this study, we observed that boronic acid played a dual role, as a protective and coupling reagent, in the Suzuki-Miyaura cross-coupling of 3-bromo-2(hydroxymethyl)phenol, and a concise synthesis of 1 employing this strategy was described. Furthermore, the conversion of 1 into 3 was also described.

\section{Results and Discussion}

Our retrosynthetic analyses of $\mathbf{1}$ and $\mathbf{3}$ are outlined in Chart 1. We envisaged that the alkenyl side chain of $\mathbf{1}$ could be introduced via the Suzuki-Miyaura cross-coupling reaction of aryl bromide $\mathbf{8}$ with the known alkenylboronic acid 9. ${ }^{8)}$ Subsequently, a deprotection reaction of the coupling product 7 would afford 1 . We also anticipated that the acid-labile protecting groups of 7 (i.e., the acetonide and methoxymethyl (MOM) groups) would be simultaneously removed under an acidic condition, which would also reduce the number of reaction steps. Additionally, the reduction of the alkenyl side chain of $\mathbf{1}$ would afford 3.

Initially, we attempted the synthesis of $\mathbf{8}$, which is a substrate for the Suzuki-Miyaura cross-coupling with the commercially available 2,5-dihydroxybenzaldehyde (10) as the starting material (Chart 2). Phenol $\mathbf{1 3}$ was prepared from $\mathbf{1 0}$ in three steps according to a known procedure, ${ }^{9,10)}$ (regioselective bromination, ${ }^{11)}$ reduction, and acetonide protection). The protection of the phenolic hydroxyl group of $\mathbf{1 3}$ afforded $\mathbf{8}$ with a yield of $94 \%$.

Next, we examined the Suzuki-Miyaura cross-coupling reaction of $\mathbf{8}$ with 9 (Chart 3). The coupling reaction proceeded smoothly employing 1.5 equivalent (equiv.) of $\mathbf{9}, 3.0$ equiv. of tert-butylamine, and $4 \mathrm{~mol} \% \mathrm{PdCl}_{2}(\mathrm{dppf}) \cdot \mathrm{CH}_{2} \mathrm{Cl}_{2}$ in $i-\mathrm{PrOH} / \mathrm{H}_{2} \mathrm{O}$ at $100^{\circ} \mathrm{C}$ for $20 \mathrm{~h}$, thereby affording the desired

* To whom correspondence should be addressed. e-mail: k-narita@tohoku-mpu.ac.jp; k-nabe@tohoku-mpu.ac.jp 
<smiles>C[N+](=O)[O-]</smiles><smiles>CCCCC/C=C/c1c(OC)ccc2c1COC(C)(C)O2</smiles>

unsaturated: violaceoid $\mathrm{A}$ (1) saturated: violaceoid C (3)<smiles>CCCCCCCC</smiles><smiles>CCCCC/C=C/B(O)O</smiles>

MOM = methoxymethyl.

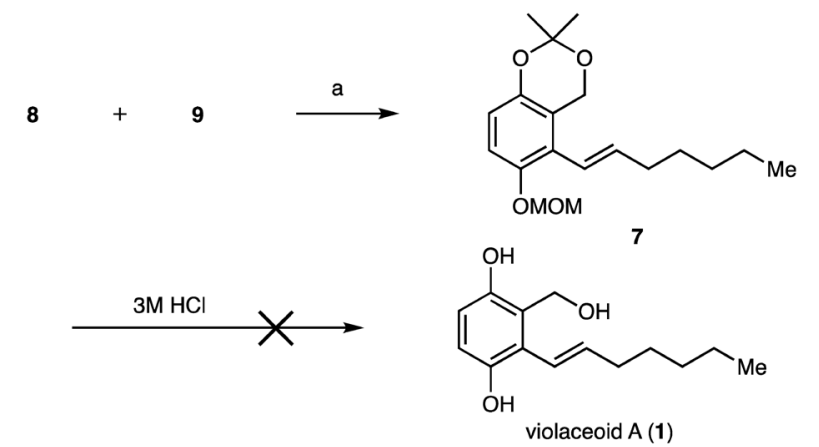

Reagents and conditions: (a) $\mathrm{PdCl}_{2}(\mathrm{dppf}) \cdot \mathrm{CH}_{2} \mathrm{Cl}_{2}$, tert-butylamine, $i-\mathrm{PrOH} / \mathrm{H}_{2} \mathrm{O}$, $100^{\circ} \mathrm{C}, 20 \mathrm{~h}, 84 \%$. dppf $=1,1^{\prime}$-bis (diphenylphosphino)ferrocene.

Chart 3. Attempted Synthesis of $\mathbf{1}$

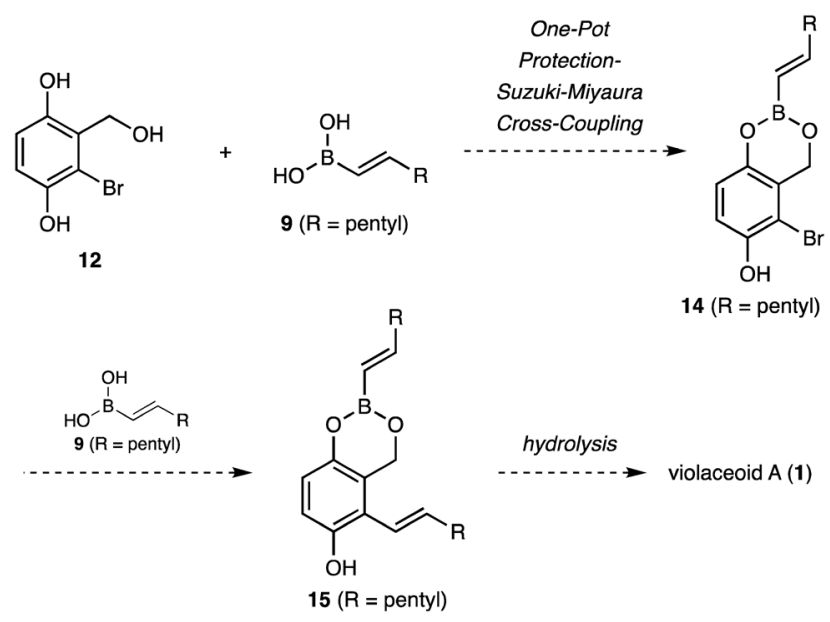

Chart 4. Revised Synthetic Plan for $\mathbf{1}$

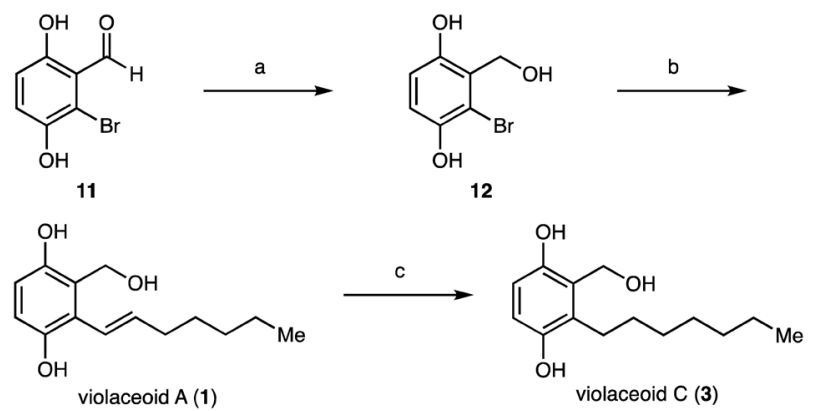

Reagents and conditions: (a) $\mathrm{NaBH}_{4}, \mathrm{EtOH}, 0^{\circ} \mathrm{C}, 30 \mathrm{~min}, 86 \%$; (b) 9 , $\mathrm{PdCl}_{2}(\mathrm{dppf}) \cdot \mathrm{CH}_{2} \mathrm{Cl}_{2}$, tert-butylamine, $i-\mathrm{PrOH} / \mathrm{H}_{2} \mathrm{O}, 100^{\circ} \mathrm{C}, 4 \mathrm{~h}, 86 \%$; and (c) $\mathrm{H}_{2}(1$ $\mathrm{atm}), 10 \% \mathrm{Pd} / \mathrm{C}$, EtOAc, r.t., $2 \mathrm{~h}, 87 \%$.

Chart 5. Syntheses of $\mathbf{1}$ and $\mathbf{3}$

material was purified by silica gel column chromatography and a pure compound 12 was obtained in $86 \%$ yield without any complication, such as the air oxidation of hydroquinone. Next, we investigated the one-pot protection/Suzuki-Miyaura cross-coupling of $\mathbf{1 2}$ with $\mathbf{9}$ under the same condition as aforementioned (1.5 equiv. of $9,3.0$ equiv. of tert-butylamine, and $4 \mathrm{~mol} \% \mathrm{PdCl}_{2}$ (dppf) $\cdot \mathrm{CH}_{2} \mathrm{Cl}_{2}$ in $i-\mathrm{PrOH} / \mathrm{H}_{2} \mathrm{O}$ at $100^{\circ} \mathrm{C}$ ). Fortunately, the reaction, which afforded 1 directly in $86 \%$ yield as the only isolable product, was completed in $4 \mathrm{~h}$. Neither $\mathbf{1 4}$ nor 15 was obtained under the condition. This reaction could be conducted on a $1.50 \mathrm{~g}$ scale to obtain $1.38 \mathrm{~g}$ of $\mathbf{1}$. Furthermore, 1 was subjected to hydrogenation $\left(\mathrm{H}_{2}\right.$ (1 atm), 10\% 


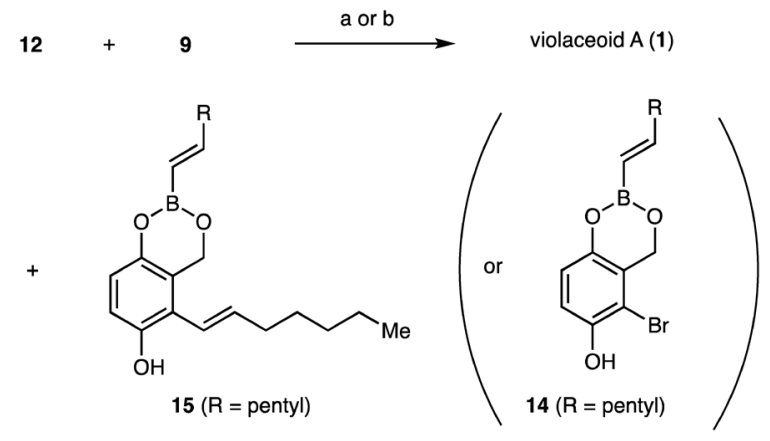

Reagents and conditions: (a) 9, $\mathrm{PdCl}_{2}(\mathrm{dppf}) \cdot \mathrm{CH}_{2} \mathrm{Cl}_{2}$, tert-butylamine, i$\mathrm{PrOH} / \mathrm{H}_{2} \mathrm{O}, 100{ }^{\circ} \mathrm{C}, 2 \mathrm{~h}, 39 \%$ for $15,35 \%$ for 1 ; (b) 9 , tert-butylamine, $i-\mathrm{PrOH} / \mathrm{H}_{2} \mathrm{O}$, $100^{\circ} \mathrm{C}, 2 \mathrm{~h}$, and $93 \%$ for 14

Chart 6. Investigation of the Suzuki-Miyaura Cross-Coupling of 12
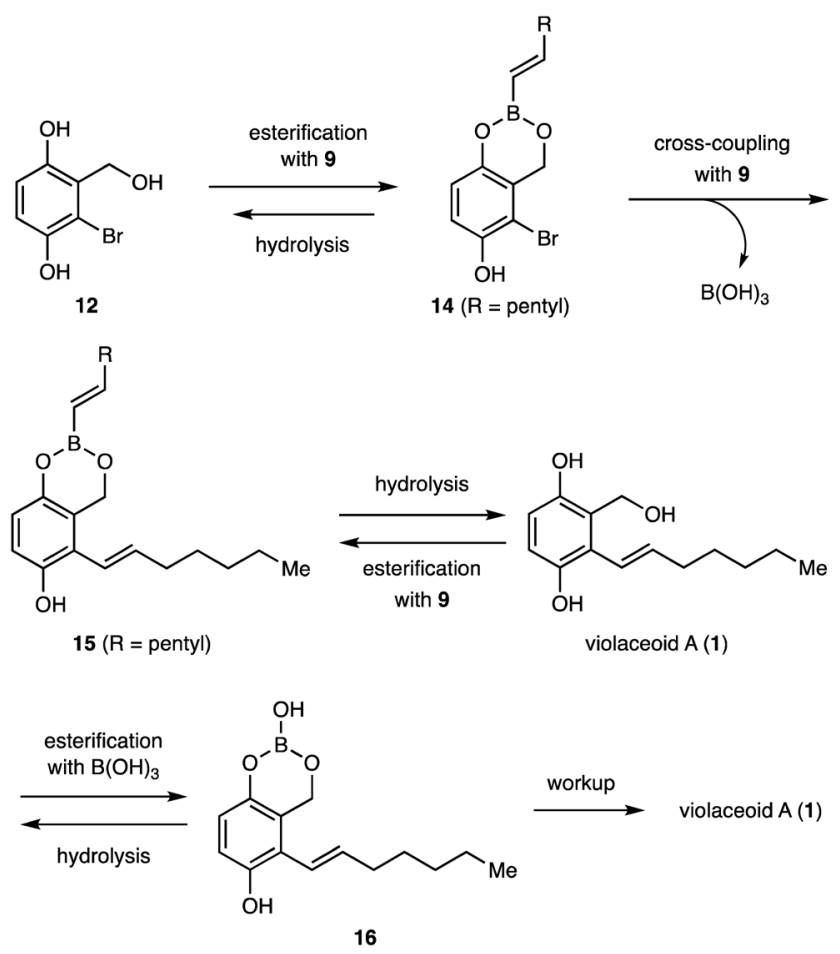

Chart 7. Plausible Reaction Pathway

$\mathrm{Pd} / \mathrm{C}$, EtOAc, room temperature (r.t.)), thus affording 3 in $87 \%$ yield. ${ }^{24)}$ The spectroscopic properties of 1 and $\mathbf{3}$ (IR, MS, and both ${ }^{1} \mathrm{H}$ - and ${ }^{13} \mathrm{C}$-NMR spectroscopies) were identical to those of naturally occurring $\mathbf{1}$ and $\mathbf{3}^{\text {.) }}$

Since the unprecedented one-pot reaction afforded $\mathbf{1}$ in good yield, the reaction of $\mathbf{1 2}$ with $\mathbf{9}$ became interesting, and we decided to investigate it in-depth. When we quenched the one-pot reaction after $1 \mathrm{~h}, \mathbf{1 5}$ was obtained in 39\% yield along with $35 \%$ yield of 1 (Chart 6). Conversely, when the reaction proceeded in the absence of the Pd catalyst, 14 was obtained in $93 \%$ yield. Contrary to these results, 1 and $\mathbf{1 2}$ gradually decomposed under the reaction condition. Both compounds were separately treated with 3.0 equiv. of tert-butylamine in $i$-PrOH$/ \mathrm{H}_{2} \mathrm{O}$ at $100{ }^{\circ} \mathrm{C}$ for $2 \mathrm{~h}$ to assess their stabilities. Resultantly, 1 and 12 were recovered in 62 and 55\% yields, respectively, indicating that both compounds were unstable under the reaction condition. Based on these results, we deduced the following reaction pathway (Chart 7). First, 12 was smoothly converted into $\mathbf{1 4}$ as a protected form of the 1,3-diol unit in $\mathbf{1 2}$ by $\mathbf{9}$. Resultantly, the stability of $\mathbf{1 2}$ was improved. Next, the Suzuki-Miyaura cross-coupling of $\mathbf{1 4}$ with another 9 proceeded to afford the coupling product $\mathbf{1 5}$. The boronate ester moiety of $\mathbf{1 5}$ was gradually hydrolyzed, resulting in the formation of 1. Furthermore, we expected that boric acid, which was generated in the reaction, contributed to the improved stability of 1 , i.e., the ester $16^{25)}$ which was generated in situ via the esterification of 1 with boric acid, suppressed the degradation of 1. Finally, the acidic workup of $\mathbf{1 6}$ afforded $\mathbf{1}$. Although all the steps were reversible reactions except for the Suzuki-Miyaura cross-coupling, we suspected that these steps with the formation of the boronate ester enabled the efficient synthesis of 1 from 12. To the best of our knowledge, this is the first report on the utilization of alkenylboronic acid as a coupling reagent and a temporary protective one.

\section{Conclusion}

We achieved the concise syntheses of $\mathbf{1}$ and $\mathbf{3}$ employing the commercially available 2,5-dihydroxybenzaldehyde (10) as the starting material (1: 69\% overall yield in three steps; 3 : $60 \%$ overall yield in four steps). The total synthesis of $\mathbf{3}$ was reported here for the first time. The key step of the synthesis was the one-pot protection/Suzuki-Miyaura cross-coupling of 12 utilizing 9. This reaction enabled the protecting-group-free and concise synthesis of $\mathbf{1}$, achieving the gram-scale synthesis of 1. Further studies are ongoing to synthesize the analogs of violaceoids possessing various alkenyl or alkyl side chains to explore their structure-activity relationships.

Acknowledgments This study was financially supported by a Japan Society for the Promotion of Science (JSPS) KAKENHI (Grant Number JP 20K15960 to K.N., 19K08663 and $16 \mathrm{~K} 08663$ to K.W.).

Conflict of Interest The authors declare no conflict of interest.

Supplementary Materials The online version of this article contains supplementary materials.

\section{References and Notes}

1) Myobatake Y., Takemoto K., Kamisuki S., Inoue N., Takasaki A., Takeuchi T., Mizushina Y., Sugawara F., J. Nat. Prod., 77, 12361240 (2014).

2) Dubin G.-M., Fkyerat A., Tabacchi R., Phytochemistry, 53, 571-574 (2000).

3) Nair M. S. R., Anchel M., Phytochemistry, 16, 390-392 (1977).

4) Sun S.-W., Ji C.-Z., Gu Q.-Q., Li D.-H., Zhu T.-J., J. Asian Nat. Prod. Res., 15, 956-961 (2013).

5) García P. A., Hernández A. P., Feliciano A. S., Castro M. Á., Mar. Drugs, 16, 292 (2018).

6) Sunassee S. N., Davies-Coleman M. T., Nat. Prod. Rep., 29, $513-$ 535 (2012).

7) Murata T., Kuboki T., Ishikawa R., Saito T., Taguchi S., Takeuchi K., Hatano E., Shimonaka M., Shiina I., J. Nat. Prod., 81, 23642370 (2018).

8) Kobayashi Y., Nakayama Y., Mizojiri R., Tetrahedron, 54, $1053-$ 1062 (1998).

9) Carr J. L., Offermann D. A., Holdom M. D., Dusart P., White A. J. P., Beavil A. J., Leatherbarrow R. J., Lindell S. D., Suttonb B. J., Spivey A. C., Chem. Commun., 46, 1824-1826 (2010). 
10) Pospíšil J., Müller C., Fürstner A., Chem. Eur. J., 15, 5956-5968 (2009).

11) Hu Y., Li C., Kulkarni B. A., Stobel G., Lobkovsky E., Torczynski R. M., Porco J. A. Jr., Org. Lett., 3, 1649-1652 (2001).

12) Reddy M. D., Kobori H., Mori T., Wu J., Kawagishi H., Watkins E. B., J. Nat. Prod., 80, 2561-2565 (2017).

13) García-Fortanet J., Debergh J. R., De Brabander J. K., Org. Lett., 7, 685-688 (2005).

14) When $\mathrm{MeOH}$ or EtOH was used as a solvent, substitution reaction of hydroxy group at hydroxymethyl moiety by alcohol was observed, and alkoxylated violaceoid A was obtained (76\% for $O$ methylated product or $24 \%$ for $O$-ethylated product). When acetone or THF was used as a solvent, the reaction became complicated and complex mixture was obtained.

15) Tay J.-H., Dorokhov V., Wang S., Nagorny P., J. Antibiot., 72, 437-448 (2019).

16) Shimada N., Urata S., Fukuhara K., Tsuneda T., Makino K., Org. Lett., 20, 6064-6068 (2018).

17) Dimakos V., Garrett G. E., Taylor M. S., J. Am. Chem. Soc., 139, 15515-15521 (2017)

18) Park S.-H., Park S., Lee C.-Y., Suh Y.-G., Shin D., Synlett, 29,
938-942 (2018).

19) Zheng H., Hall D. G., Tetrahedron Lett., 51, 4256-4259 (2010).

20) Nagata W., Okada K., Aoki T., Synthesis, 1979, 365-368 (1979).

21) Karlsson C., Huang H., Strømme M., Gogoll M., Sjödin M., J. Phys. Chem. C, 118, 23499-23508 (2014).

22) Chakraborty M., Brzozowski C. F., Novak M., J. Phys. Org. Chem., 25, 1236-1242 (2012).

23) Lee K.-S., Jeong M.-H., Kim Y.-J., Lee S.-B., Lee J.-S., Chem. Mater., 24, 1443-1453 (2012).

24) Attempt to synthesize violaceoid C (3) directly via Suzuki-Miyaura cross-coupling of hydroquinone $\mathbf{1 2}$ with heptylboronic acid under the same condition as the synthesis of violaceoid A was failed, and 12 was gradually decomposed. This may be due to instability of corresponding alkyl boronate ester and low reactivity of heptylboronic acid under the reaction condition.

25) Although we could not isolate ester 16, the stability of violaceoid A (1) was improved in the presence of boric acid. When violaceoid A (1) was treated with 1.5 equiv. of boric acid and 3.0 equiv. of tertbutylamine in $i-\mathrm{PrOH} / \mathrm{H}_{2} \mathrm{O}$ at $100{ }^{\circ} \mathrm{C}$ for $2 \mathrm{~h}, 82 \%$ of 1 was recovered. 